\title{
A Hydraulic-and-electric Robot Arm for Mobile Manufacturing
}

\author{
Peng Gao , Anye Ren and Zong Wei \\ Aerospace System Engineering Shanghai, Shanghai, China \\ pompon_gp@163.com
}

\begin{abstract}
Keywords: Hydraulic-and-electric; Robot Arm; Mobile Manufacturing.
Abstract. This paper proposes a hydraulic-and-electric robot arm for mobile riveting manufacturing. A hydraulic-and-electric robot arm prototype equipped on $\mathrm{AGV}$ is designed with $1.5 \mathrm{~m}$ stretching length, $30 \mathrm{~kg}$ load and $250 \mathrm{~kg}$ self weight, which is lighter than commercial robot arm products. It consists of 3 hydraulic actuating joints for heavy load and 4 electric actuating joints for force control. The hydraulic actuating joint is a 3-layer rotatable cylinder with higher reliability, lower leak and $360^{\circ}$ output. The electric actuating joint is an integration of AC servo motor, harmonic reducer, absolute angle sensor and precise torque sensor. In this paper, the hydraulic and electric actuating joint prototypes are fabricated and tested. In future, the hydraulic-and-electric robot arm prototype will be fabricated and tested for actual riveting processing.
\end{abstract}

\section{Introduction}

Mobile manufacturing has become an important development trend of intelligent manufacturing. In particular, the traditional fixed manufacturing has been not able to meet the needs of large-scale manufacturing, such as aircraft, ship, high speed railway vehicle, wind power equipment. The robot manufacturer and user are exploring the possibility of mobile robotic manufacturing mainly composed of robot arm and automated guided vehicle (AGV).

Considering the carrying capability of AGV, the self weight of robot arm is an important issue in the condition of power density limitation of commercial electrical robot arm products. Compared to electric actuation, hydraulic actuation has higher power density together with high force and torque to make the robotic system smaller and faster [1]. In recent years, hydraulic actuating joints (HAJ) is wildly used in hydraulic robot system[2], variable geometry truss[3], legged robot[4], robot hand[5], etc. Most of robotic hydraulic actuators are longitudinal hydraulic cylinder which may limit the output angle of robotic rotation joint. However, rotatable hydraulic cylinder has wider adaptability, but it is difficult to make a rotatable hydraulic cylinder with higher reliability, lower leak and $360^{\circ}$ output. In addition, in order to meet manufacturing flexibility, the robot arm should has redundant freedom and force-position control ability.

In this paper, a hydraulic-and-electric robot arm for mobile riveting manufacturing is proposed. A prototype of hydraulic-and-electric robot arm equipped on $\mathrm{AGV}$ for mobile riveting manufacturing is designed as $1.5 \mathrm{~m}$ stretching length, $30 \mathrm{~kg}$ load and $250 \mathrm{~kg}$ self weight, which is lighter than commercial robot arm products. It consists of 3 hydraulic actuating joints for heavy load and 4 electric actuating joints for force control. The hydraulic actuating joint is a 3-layer rotatable cylinder with higher reliability, lower leak and $360^{\circ}$ output. The electric actuating joint is an integration of AC servo motor, harmonic reducer, absolute angle sensor and precise torque sensor. The hydraulic and electric actuating joint prototypes are fabricated and tested. In future, the hydraulic-and-electric robot arm prototype will be fabricated and tested for actual riveting processing.

\section{Hydraulic-and-electric Robot Arm}

In this paper, the riveting manufacturing requires the robot arm with the minimum $1.5 \mathrm{~m}$ stretching length and $30 \mathrm{~kg}$ load. In addition, the existing VGA has the maximum 400kg carrying capability. Tough meeting the stretching length and load requirements, the commercial robot arms have higher self weight, for example, KR 30 made by KUKA inc. with $665 \mathrm{~kg}$ self weight. In addition, in order to 
improve the riveting manufacturing flexible, the robot arm also need a redundant freedom configuration. Normally, the commercial robot arms have the maximum 6 freedoms. Hence, it is necessary to design a Robot Arm with hydraulic actuating joints to improve the power density and 7 freedom to improve the manufacturing flexible.

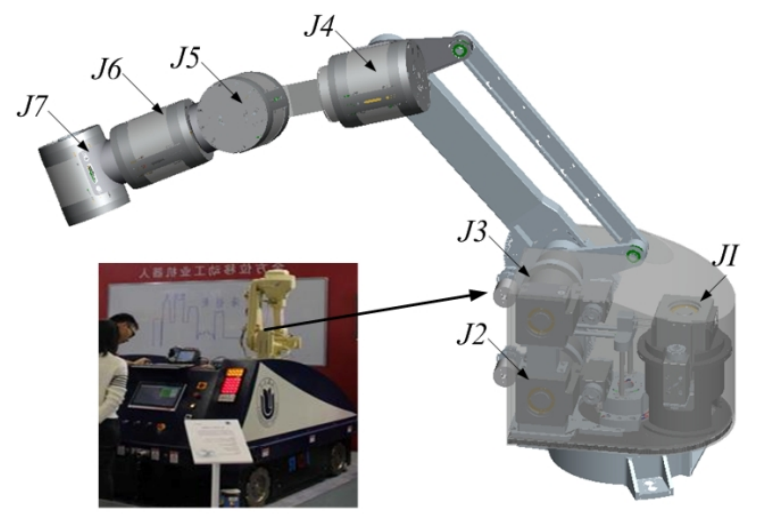

Fig. 1. Design schematic of hydraulic-and -electric robot arm.

As shown in Fig.1, the robot arm is designed as a series mechanism with 7 freedom and $1.55 \mathrm{~m}$ stretching length. In the condition of carrying $30 \mathrm{~kg}$ load, $\mathrm{J} 1, \mathrm{~J} 2$ and $\mathrm{J} 2$ can provide the maximum $500 \mathrm{Nm}$ output torque; J4 and $\mathrm{J} 5$ can provide the maximum $200 \mathrm{Nm}$ output torque; J6 and $\mathrm{J} 7$ can provide the maximum $100 \mathrm{Nm}$ output torque. The electric actuating joint with $500 \mathrm{Nm}$ is very heavy because of the weight of motor and speed reducer. By initially estimating, its weight will be more than $50 \mathrm{~kg}$. The total weight of J1, J2 and J3 is more than $150 \mathrm{~kg}$, which can't be supported by the AGV easily. Thus J1, J2 and $\mathrm{J} 3$ are designed as hydraulic actuating joints. The electric actuating joint with $200 \mathrm{Nm}$ is about $15 \mathrm{~kg}$, and that with $100 \mathrm{Nm}$ is about $10 \mathrm{~kg}$. When providing less torque, the advantage of power density of hydraulic actuator is not obvious. Therefore, J4-J7 select electric actuation.

\section{Hydraulic Actuating Joint}

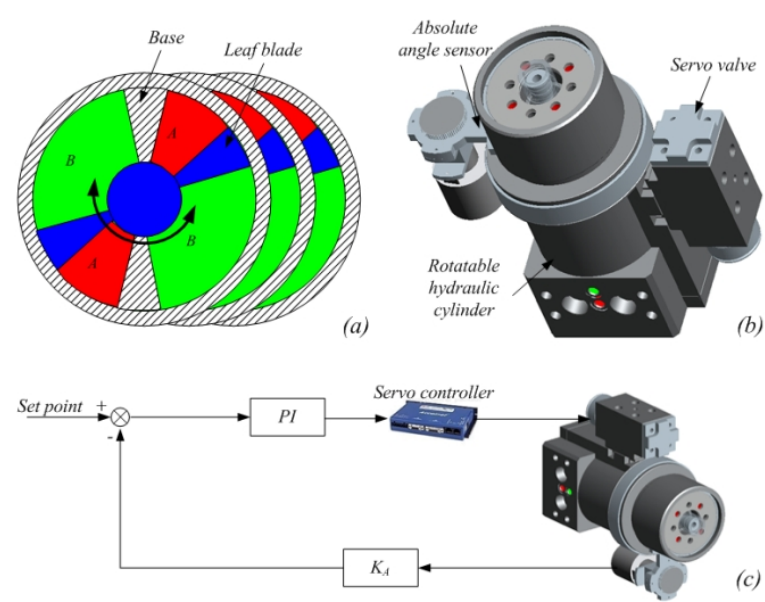

Fig. 2. Schematic of hydraulic actuating joint.

The hydraulic actuating joint is designed as a rotatable hydraulic cylinder with 3-layer leaf blades in series to realize a $360^{\circ}$ continuous rotatable output. Each leaf blade realizes $120^{\circ}$ continuous rotation as shown in Fig. 2(a), in which the hydraulic error between A and B cavities can change the rotating and torque direction. In order to improve the system reliability, the leaf blades and shell are made of the special steal as harder as possible to reduce the abrasion, and have the clearance as small as possible to reduce hydraulic oil leak. It is obvious that there may be a proof hydraulic seal problem between leaf blade layer and between leaf blade and shell, but which has been solved by a static hydraulic floating seal technique.

The hydraulic actuating joint mainly consists of a rotatable hydraulic cylinder, a servo valve actuated by a DC brushless motor by Maxon Inc., and a absolute angle sensor, as shown in Fig. 2(b). 
A closed loop control system can be established as showing in Fig. 2(c). The output angle from the absolute angle sensor is compared with the set point. A PI controller is used to control the servo controller of the servo valve.

\section{Electric Actuating Joint}

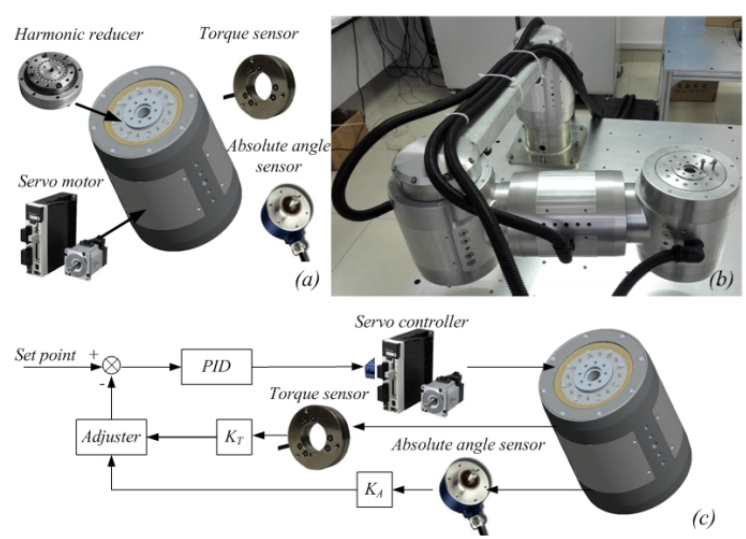

Fig. 3. Electric actuating joint.

The electric actuating joint mainly consists of a servo motor, a harmonic reducer, a absolute angle sensor and a torque sensor, as shown in Fig. 3(a). J4 and J5 can output the maximum 200Nm with a $100 \mathrm{~W}$ AC servo motor by Panasonic Inc., and J6 and J7 can output the maximum $100 \mathrm{Nm}$ with a $50 \mathrm{~W}$ AC servo motor. They have the same mechanism configuration. Fig. 3(b) illustrates a fabricates structure. Each electric actuating joint is connected in to a integrated controller with EtherCAT communication.

In the controller, a hybrid torque-angle control closed loop is established as shown in Fig. 3(c), which has a common PID controller and a servo controller in velocity control mode. The torque sensor measures the load torque, and the absolute angle sensor measures the output absolute angle. The two measure values are changed to eliminate the influence of torque and angle units. Then, the adjuster selects torque and angle control mode.

\section{Experiments}

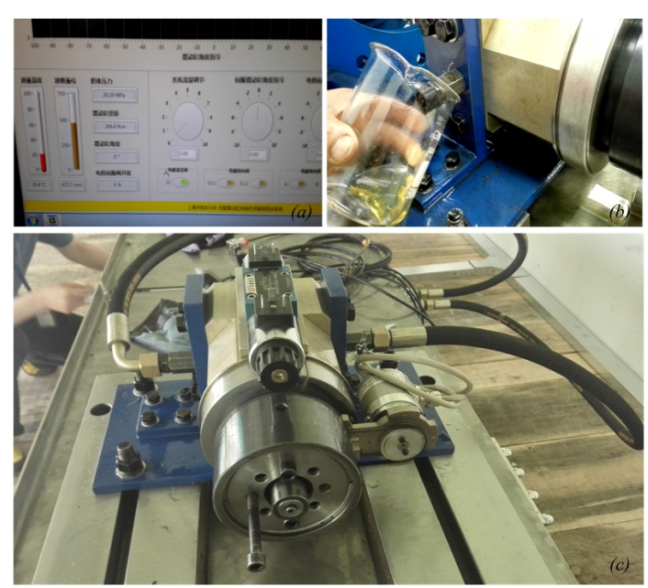

Fig. 4. Experiments of hydraulic actuating joint.

The weights from $\mathrm{J} 1$ to $\mathrm{J} 7$ are respectively $23.6 \mathrm{~kg}, 23.6 \mathrm{~kg}, 23.6 \mathrm{~kg}, 13.5 \mathrm{~kg}, 13.5 \mathrm{~kg}, 11.4 \mathrm{~kg}$ and $11.4 \mathrm{~kg}$. The total weight of seven joints is about $120 \mathrm{~kg}$. In the condition of $1.5 \mathrm{~m}$ stretching length, the self weight of the fabricated robot arm can be controlled less than $250 \mathrm{~kg}$. The maximum static output torques from $\mathrm{J} 1$ to $\mathrm{J} 7$ with $20 \mathrm{MPa}$ hydraulic pressure is $505 \mathrm{Nm}, 511 \mathrm{Nm}$ and $507 \mathrm{Nm}$, which are also according to the design requirement. 
Fig. 4(a) shows a compression resistance of 20.20Mpa. Fig. 4(b) shows a hydraulic leak experiment of the hydraulic actuating joint. The experimental results are illustrated in Table 1 . The static system leak is less than common hydraulic valve $(1 \mathrm{~L} / \mathrm{min})$, which is very suitable for robotic actuation.

Table 1. Results of hydraulic leak experiments.

\begin{tabular}{ll}
\hline Hydraulic pressure & Maximum leak \\
\hline $5 \mathrm{MPa}$ & $10 \mathrm{~mL} / \mathrm{min}$ \\
$10 \mathrm{MPa}$ & $20 \mathrm{~mL} / \mathrm{min}$ \\
$15 \mathrm{MPa}$ & $50 \mathrm{~mL} / \mathrm{min}$ \\
$20 \mathrm{Mpa}$ & $200 \mathrm{~mL} / \mathrm{min}$ \\
\hline
\end{tabular}

As shown in Fig. 4(c), the hydraulic actuating joint is controlled by a closed loop system. After resolving the hysteretic influence of the hydraulic valve, the results of the output angle accuracy experiments are in Table 2. With 20MPa hydraulic pressure, the output angle accuracy is controlled in $\pm 0.20^{\circ}$.

Table 2. Results of output angle accuracy experiments.

\begin{tabular}{ll}
\hline Set angle & Output error \\
\hline $0^{\circ}$ & $+0.15^{\circ}$ \\
$120^{\circ}$ & $+0.16^{\circ}$ \\
$240^{\circ}$ & $+0.12^{\circ}$ \\
$360^{\circ}$ & $-0.13^{\circ}$ \\
\hline
\end{tabular}

\section{Conclusion}

In this work, we proposed a hydraulic-and-electric robot arm for mobile riveting manufacturing. It is designed with $1.5 \mathrm{~m}$ stretching length, $30 \mathrm{~kg}$ load and $250 \mathrm{~kg}$ self weight. It consists of 3 hydraulic actuating joints for heavy load and 4 electric actuating joints for force control. Under the use of hydraulic actuating joints, itself weight is reduced. We have finished the prototype of 3 hydraulic actuating joints and 4 electric actuating joints. Though the output angle accuracy has been controlled, there are some problems, such as sensor libration, hydraulic valve hysteresis, which need to be resolved to improve the output angle accuracy to $0.05^{\circ}$ for actual mobile riveting manufacturing. In the future work, we will finish the integration of seven joints and improve the control method of the robot arm.

\section{Acknowledgements}

This work was financially supported by Shanghai Science and Technology Commission foundation under grant no. 13DZ1108300, 14111104500, and 14111104501, and by NC Technology Project of PRC under grant no. 2014ZX04001131.

\section{References}

[1] Jang S, Lee G, Kim H, et al. Hydraulic actuators in application of robot manipulator, 2012 IEEE Int. Conf. on Automation Science and Engineering (CASE). 2012:924-925.

[2] Focchi M, Guglielmino E, Semini C, et al. Control of a hydraulically-actuated quadruped robot leg, IEEE Advanced Intelligent Mechatronics (AIM)on Robotics \& Automation. IEEE, 2010:4182-4188.

[3] Rost S, Uhlemann M, Modler K, et al. On the joint design and hydraulic actuation of octahedron VGT robot manipulators, 2011 IEEE/ASME Int. Conf. on Advanced Intelligent Mechatronics (AIM). IEEE, 2011:92-97.

[4] Yan H, Li Z, Lin X. Kinematics analysis of double hydraulic actuated one-legged robot attitude adjustment mechanism, 2014 Int. Conf. on Informatics and Computing (PIC). IEEE, 2014.

[5] Kang T, Kaminaga H, Nakamura Y. A robot hand driven by hydraulic cluster actuators, 2014 14th IEEE-RAS Int. Conf. on Humanoid Robots. IEEE, 2014:39-44. 